\title{
Aggressive treatment in early rheumatoid arthritis: a randomised controlled trial
}

C H M van Jaarsveld, J W G Jacobs, M J van der Veen, A A M Blaauw, A A Kruize, D M Hofman, H L M Brus, G A van Albada-Kuipers, A H M Heurkens, E J ter Borg, H C M Haanen, C van Booma-Frankfort, Y Schenk, J W J Bijlsma on behalf of the Rheumatic Research Foundation Utrecht, The Netherlands

Department of Rheumatology and Clinical Immunology, University Medical Centre, PO Box 85500, 3508 GA Utrecht, The Netherlands C H M van Jaarsveld J W G Jacobs A A M Blaauw A A Kruize D M Hofman J W J Bijlsma

\section{Department of} Rheumatology, Hospital Sint Jansdal, PO Box 138, 3840 AC Harderwijk, The Netherlands $\mathrm{M} J$ van der Veen

Department of Rheumatology, Hospital Hilversum, PO Box 10016, 1201 DA Hilversum,

The Netherlands D M Hofman H L M Brus

Department of Rheumatology, Eemland Hospital, PO Box 1502, 3800 MB Amersfoort, The Netherlands G A van Albada-Kuipers A H M Heurkens

Department of Rheumatology, Sint Antonius Hospital, Koekoekslaan 1, 3435 CM Nieuwegein, The Netherlands E J ter Borg H C M Haanen

Department of Rheumatology, Diakonessen Hospital, Bosboomstraat 1, 3582 KE Utrecht,

The Netherlands

C van Booma-Frankfort Y Schenk

Correspondence to: Dr Jacobs

Email:

J.W.J.Bijlsma@DIGD.AZU.NI

Accepted for publication 12 January 2000

\section{Abstract}

Objectives-To compare three therapeutic strategies using slow acting antirheumatic drugs (SAARDs) in early rheumatoid arthritis (RA), for their disease modifying properties, toxicity, and lag time until treatment effect.

Methods-Patients with recent onset RA from six hospitals were randomly assigned to immediate initiation of one of three treatment strategies: (I) a "mild SAARD with a long lag time" (hydroxychloroquine, if necessary replaced by auranofin); (II) a "potent SAARD with a long lag time" (intramuscular gold, if necessary replaced by D-penicillamine); (III) a "potent SAARD with a short lag time" (methotrexate, if necessary replaced by sulfasalazine). Comparisons included two years of follow up.

Results-All SAARD strategies reduced mean disease activity. A greater percentage of patients improved clinically with strategies II and III than with strategy I: percentages of patients improved on joint score with strategies II and III $(79 \%$ and $82 \%$, respectively), which was statistically different from strategy I $(66 \%)$. The same was true for remission percentages: $31 \%$ and $24 \% v 16 \%$, respectively). Longitudinal analysis showed significantly less disability with strategy III, and a lower erythrocyte sedimentation rate with strategy II than with strategy I. In addition, radiological damage after one and two years, was significantly lower in strategies II and III (at two years median scores were 11 and $10 v 14$ in strategy $I, p<0.05)$. Toxicity was increased in strategy II compared with the other strategies.

Conclusion-Strategy III, comprising methotrexate or sulfasalazine, produced the best results weighing effectiveness and toxicity. Strategy I (hydroxychloroquine or auranofin) was slightly less effective, and strategy II (intramuscular gold or D-penicillamine) was associated with increased toxicity.

(Ann Rheum Dis 2000;59:468-477)

Rheumatoid arthritis (RA) is a chronic disease characterised by symmetrical polyarthritis. Pharmacotherapy consists of non-steroidal anti-inflammatory drugs (NSAIDs), slow acting antirheumatic drugs (SAARDs), and corticosteroids. Traditionally, RA treatment in- volved conservative management with NSAIDs given for long periods. If insufficiently effective, NSAIDs were supplemented with an SAARD. SAARDs are believed to influence the outcome of RA positively in contrast with NSAIDs, which are only symptom relieving. In the past decade the therapeutic management has changed towards more aggressive management. In line with other reports, ${ }^{12}$ our previous results from the Utrecht Rheumatoid Arthritis Cohort show that after one year early intervention with SAARDs is more effective than treatment with NSAIDs only. ${ }^{3}$

The SAARDs that are used to treat RA differ in their disease modifying properties, toxicity, and lag time until treatment effect. In general, the more potent SAARDs are also believed to be the more toxic. Antimalarial drugs (hydroxychloroquine) are thought to be the least effective and less toxic than the other SAARDs. The maximum beneficial effects of hydroxychloroquine are not seen until after three to six months. ${ }^{4}$ Oral gold (auranofin) has similar characteristics. ${ }^{56}$ Intramuscular gold and D-penicillamine are more potent but also more toxic, ${ }^{7-9}$ the lag time between the start and treatment effect is relatively long (more than three months). Many rheumatologists regard methotrexate as a potent and toxic drug, and therefore only prescribe methotrexate if other SAARDs are insufficiently effective. The effect of methotrexate has been shown to start within four to six weeks. ${ }^{10}$ Sulfasalazine is also regarded as an SAARD with a relatively short lag time. ${ }^{411}$

Thus the most commonly used SAARDs can be classified into three groups: mild with a relatively long lag time (hydroxychloroquine, auranofin), more potent with an expected long lag time (intramuscular gold, D-penicillamine), and potent with a relatively short lag time (methotrexate, sulfasalazine). It is not clear whether one of these SAARD groups is superior in the treatment of early RA. In this study the effectiveness, lag time, and side effects of the three different strategies according to the three groups described above are compared after one and two years of follow up.

\section{Methods}

PATIENTS

The study was designed as a prospective open label randomised controlled trial. Since 1990 all patients with recent onset RA (according to the American Rheumatism Association criteria), ${ }^{12}$ from all (six) rheumatological centres in 
Table 1 Baseline characteristics*

\begin{tabular}{|c|c|c|c|c|c|}
\hline Variable, unit (range) & $\begin{array}{l}\text { Strategy I } \\
(n=107)\end{array}$ & $\begin{array}{l}\text { Strategy II } \\
(n=101)\end{array}$ & $\begin{array}{l}\text { Strategy III } \\
(n=105)\end{array}$ & $\begin{array}{l}\text { Dropouts } \\
(n=31)\end{array}$ & $\begin{array}{l}\text { Patients who were } \\
\text { not randomly } \\
\text { assigned }(n=52)\end{array}$ \\
\hline Female sex, \% & 69 & 65 & 64 & 52 & 81 \\
\hline Rheumatoid factor positive, \% & 67 & 56 & 65 & 55 & 69 \\
\hline \multicolumn{6}{|l|}{ Age, years } \\
\hline Mean & 56 & 55 & 57 & $67 \dagger$ & 55 \\
\hline 10-90 Centiles & $37-74$ & $35-73$ & $37-73$ & $38-79$ & $30-73$ \\
\hline \multicolumn{6}{|l|}{ Primary end points } \\
\hline \multicolumn{6}{|l|}{ Disability score $(0-3)$} \\
\hline Mean & 1.4 & 1.3 & 1.3 & 1.5 & $1.0 \dagger$ \\
\hline 10-90 Centiles & $0.5-2.5$ & $0.1-2.4$ & $0.3-2.4$ & $0.4-2.6$ & $0.1-2.1$ \\
\hline \multicolumn{6}{|l|}{ Pain score, $\mathrm{mm}(0-100)$} \\
\hline Mean & 46 & 43 & 44 & 43 & $31 \dagger$ \\
\hline 10-90 Centiles & $9-86$ & $3-82$ & 9-92 & $1-96$ & $1-72$ \\
\hline \multicolumn{6}{|l|}{ Joint score $(0-534)$} \\
\hline Mean & 141 & 147 & 142 & 152 & 110 \\
\hline 10-90 Centiles & $35-306$ & $38-280$ & $44-279$ & $47-357$ & $20-226$ \\
\hline \multicolumn{6}{|l|}{$\mathrm{ESR}, \mathrm{mm} / 1 \mathrm{st} \mathrm{h}(0-140)$} \\
\hline Mean & 42 & 41 & 43 & 41 & 39 \\
\hline 10-90 Centiles & $11-86$ & $9-88$ & $14-88$ & $14-87$ & $8-92$ \\
\hline \multicolumn{6}{|l|}{ Radiological damage (0-448) } \\
\hline Median & 2 & 2 & 2 & 2 & 2 \\
\hline 10-90 Centiles & $0-12$ & $0-11$ & $0-13$ & $0-6$ & $0-10$ \\
\hline \multicolumn{6}{|l|}{ Secondary end points } \\
\hline \multicolumn{6}{|l|}{ Wellbeing, $\mathrm{mm}(0-100)$} \\
\hline Mean & 49 & 50 & 49 & 48 & 39 \\
\hline 10-90 Centiles & $6-90$ & $6-82$ & $12-92$ & $12-92$ & $2-80$ \\
\hline \multicolumn{6}{|l|}{ Grip strength, $\mathrm{kPa}(0-120)$} \\
\hline Mean & 30 & 33 & 31 & 24 & 35 \\
\hline $10-90$ Centiles & $4-58$ & $6-67$ & $5-58$ & $1-43$ & $9-59$ \\
\hline \multicolumn{6}{|l|}{ Haemoglobin, $\mathrm{mmol} / 1$} \\
\hline Mean & 7.8 & 8.0 & 8.0 & 8.1 & 7.8 \\
\hline 10-90 Centiles & $6.5-9.0$ & $6.9-9.1$ & $6.8-9.0$ & $7.1-9.2$ & $6.7-9.0$ \\
\hline \multicolumn{6}{|l|}{ Morning stiffness, $\min (0-720)$} \\
\hline Median & 60 & 60 & 60 & 60 & 30 \\
\hline 10-90 Centiles & $10-360$ & $5-180$ & $3-360$ & $1-288$ & $0-162$ \\
\hline \multicolumn{6}{|l|}{$\mathrm{C}$ reactive protein, $\mathrm{mg} / \mathrm{l}$} \\
\hline Median & 26 & 20 & 16 & 18 & 18 \\
\hline 10-90 Centiles & $0-94$ & $0-85$ & $0-72$ & $0-79$ & $0-70$ \\
\hline \multicolumn{6}{|l|}{ Platelet count $\times 10^{9} / 1$} \\
\hline Median & 321 & 332 & 317 & 330 & 317 \\
\hline 10-90 Centiles & $215-503$ & $220-482$ & $219-483$ & $218-436$ & $243-522$ \\
\hline
\end{tabular}

*Higher values indicate more active disease, with the exception of values for grip strength and haemoglobin.

Mean was presented for normal distribution of the variables, and median for a skew distribution. Presented ranges are theoretical ranges.

†Dropouts had a significantly higher age than all other groups (analysis of variance (ANOVA), $p=0.002$ ).

Patients who were not randomly assigned differed significantly from all other groups: less disability (ANOVA, $p=0.05$ ) and lower pain score (ANOVA, $\mathrm{p}=0.04$ ).

the Utrecht region of the Netherlands, were asked to participate in a randomised prospective clinical trial. Disease duration had to be less than one year; most patients were enrolled shortly after the diagnosis was established. One university hospital and five general hospitals are included in this multicentre trial, covering a

Table 2 Number of patients whose assigned strategies were discontinued and reasons for discontinuation

\begin{tabular}{|c|c|c|c|c|c|c|}
\hline \multirow[b]{2}{*}{ Strategy $y^{\star}$} & \multirow[b]{2}{*}{$\begin{array}{l}\text { Period } \\
\text { (years) }\end{array}$} & \multirow{2}{*}{$\begin{array}{l}\text { Patients who } \\
\text { discontinued } \\
\text { strategy } \\
\text { No (\%) }\end{array}$} & \multicolumn{4}{|c|}{ Reasons for discontinuation $t$} \\
\hline & & & $\begin{array}{l}\text { Adverse } \\
\text { reaction }\end{array}$ & Ineffectiveness & $\begin{array}{l}\text { Adverse reaction } \\
\text { and ineffectiveness }\end{array}$ & Other \\
\hline \multirow[t]{3}{*}{ I } & $0-1$ & $12(11)$ & 0 & 12 & 0 & 0 \\
\hline & $1-2$ & $17(16)$ & 5 & 10 & 2 & 0 \\
\hline & $0-2$ & $29(27)$ & 5 & 22 & 2 & 0 \\
\hline \multirow[t]{3}{*}{ II } & $0-1$ & $4(4)$ & 1 & 2 & 0 & 1 \\
\hline & $1-2$ & $26(26)$ & 15 & 9 & 1 & 1 \\
\hline & $0-2$ & $30(30)$ & 16 & 11 & 1 & 2 \\
\hline \multirow[t]{3}{*}{ III } & $0-1$ & $11(10)$ & 4 & 4 & 1 & 2 \\
\hline & $1-2$ & $10(10)$ & 3 & 7 & 0 & 0 \\
\hline & $0-2$ & $21(20)$ & 7 & 11 & 1 & 2 \\
\hline
\end{tabular}

* Strategy I: mild slow acting antirheumatic drug (SAARD) with an expected long lag time: hydroxychloroquine or auranofin.

Strategy II: potent SAARD with an expected long lag time: intramuscular gold or D-penicillamine. Strategy III: potent SAARD with a relatively short lag time: methotrexate or sulfasalazine.

Discontinuation rates after one and two years were not statistically significantly different between the three strategies.

†Results are shown as number of patients. population of approximately one million people. The following exclusion criteria were applied: age $<17$ years; comorbid conditions that might interfere with one of the therapeutic strategies (such as malignancy, cardiac, respiratory, hepatic, and renal insufficiency); previous or current treatment with SAARDs, corticosteroids, cytotoxic or immunosuppressive drugs; possible pregnancy or breast feeding; psychiatric or mental disturbances that make adherence to study protocol unlikely. All patients signed informed consent; the ethical committees of all participating hospitals approved the study design. Baseline characteristics of patients eligible for the study but objecting to randomisation were compared with those of randomised patients to see if any selection bias had occurred.

\section{TREATMENT}

Patients entering the study were randomly assigned to one of three therapeutic strategies:

Strategy I: Treatment was started with hydroxychloroquine (400 mg daily): a mild SAARD with an expected long lag time until treatment effect; if necessary replaced by auranofin (6-9 mg daily), an SAARD with the same characteristics. 
Table 3 Changes from baseline in primary end points

\begin{tabular}{|c|c|c|c|c|}
\hline \multirow[b]{2}{*}{ Primary end points $†$} & \multicolumn{3}{|l|}{ Change from baseline ${ }^{\star}$} & \multirow{2}{*}{$\begin{array}{l}\text { Difference } \\
\text { between } \\
\text { strategies }\end{array}$} \\
\hline & Strategy $I(n=107)$ & Strategy II $(n=101)$ & Strategy III $(n=105)$ & \\
\hline \multicolumn{5}{|l|}{1 year } \\
\hline Disability score & $-0.3(-0.5$ to -0.2$)$ & $-0.4(-0.5$ to -0.2$)$ & $-0.4(-0.5$ to -0.3$)$ & \\
\hline Pain score, $\mathrm{mm}$ & $-21(-27$ to -15$)$ & $-18(-25$ to -12$)$ & $-24(-28$ to -18$)$ & \\
\hline Joint score & $-74(-99$ to -49$)$ & $-93(-118$ to -67$)$ & $-95(-113$ to -78$)$ & \\
\hline $\mathrm{ESR}, \mathrm{mm} / 1 \mathrm{st} \mathrm{h}$ & $-16(-20$ to -12$)$ & $-18(-24$ to -12$)$ & $-20(-25$ to -16$)$ & \\
\hline Radiological damage & & & & $\neq$ \\
\hline Median & +6 & +3 & +2 & \\
\hline 10-90 Centiles & $0-25$ & $0-15$ & $0-14$ & \\
\hline \multicolumn{5}{|l|}{2 years } \\
\hline Disability score & $-0.3(-0.5$ to -0.2$)$ & $-0.4(-0.6$ to -0.2$)$ & $-0.3(-0.4$ to -0.2$)$ & \\
\hline Pain score, $\mathrm{mm}$ & $-22(-27$ to -16$)$ & $-25(-31$ to -19$)$ & $-21(-27$ to -16$)$ & \\
\hline Joint score & $-89(-111$ to -67$)$ & $-104(-128$ to -80$)$ & $-86(-106$ to -66$)$ & \\
\hline $\mathrm{ESR}, \mathrm{mm} / 1 \mathrm{st} \mathrm{h}$ & $-19(-24$ to -14$)$ & $-21(-27$ to -16$)$ & $-20(-24$ to -15$)$ & \\
\hline Radiological damage & & & & $\ddagger$ \\
\hline Median & +12 & +9 & +8 & \\
\hline 10-90 Centiles & $0-48$ & $0-28$ & $0-37$ & \\
\hline
\end{tabular}

*Values are the mean change from baseline and $95 \%$ CI for the mean. For radiological damage values are median change and the $10-90$ centiles. Negative values indicate improvement for all end points.

†Ranges for end point measures are as follows: disability score, 0 to 3; pain score, 0 to $100 \mathrm{~mm}$; joint score, 0 to 534 ; erythrocyte sedimentation rate, 1 to $140 \mathrm{~mm} / 1 \mathrm{st} \mathrm{h}$; radiological damage score, 0 to 448 .

‡Differences between strategies I and II, and between I and III were significant $(p<0.05)$, but not between strategies II and III (Mann-Whitney U test).

Strategy II: Treatment with intramuscular gold (aurothioglucose, IM gold, $50 \mathrm{mg}$ weekly): a more potent and toxic SAARD with an expected long lag time; if necessary replaced by D-penicillamine (500-750 $\mathrm{mg}$ daily), an SAARD with the same characteristics.

Strategy III: Treatment with oral methotrexate $(7.5-15 \mathrm{mg}$ weekly): a relatively fast acting, potent SAARD; if necessary replaced by sulfasalazine (2-3 g daily), an SAARD with the same characteristics.

Randomisation was performed by an independent person, in blocks of 100 patients per hospital. The initial SAARD (hydroxychloroquine, IM gold, or methotrexate) was continued unless adverse reactions or ineffectiveness made discontinuation inevitable in the view of the attending doctor, in which case the second SAARD of that particular strategy was given. Treatment with an SAARD other than the initial or the second SAARD was regarded as discontinuation of the therapeutic strategy. $\mathrm{Pa}-$ tients who could stop taking drugs owing to remission were not considered as having discontinued the strategy.
Use of NSAIDs and analgesics was allowed in all strategies. Oral corticosteroids and intraarticular injections with corticosteroids were avoided. Criteria for dose adjustment due to adverse reactions were described in detail in the study protocol. After one year of treatment responses were assessed for each patient. When improvement of at least $50 \%$ from the start of the drug was seen in at least three of four variables (pain, joint score, morning stiffness, erythrocyte sedimentation rate (ESR)) the SAARD was continued. The initial SAARD was stopped in patients who did not meet these criteria, and treatment with the second SAARD from the strategy was started. If a patient fulfilled the remission criteria at three subsequent visits (six months), the dosage of the SAARD was reduced to half-that is, halved dosages of hydroxychloroquine, auranofin, D-penicillamine, sulfasalazine were continued daily and halved dosages of IM gold, methotrexate were continued weekly. Patients were considered to be in remission when the duration of morning stiffness was $\leqslant 15$ minutes, the pain score was $\leqslant 10 \mathrm{~mm}$, the

Table 4 Changes from baseline in secondary end points

\begin{tabular}{|c|c|c|c|c|}
\hline \multirow[b]{2}{*}{ Secondary end points $\dagger$} & \multicolumn{3}{|l|}{ Change from baseline ${ }^{*}$} & \multirow{2}{*}{$\begin{array}{l}\text { Difference } \\
\text { between } \\
\text { strategies }\end{array}$} \\
\hline & Strategy $I(n=107)$ & Strategy II $(n=101)$ & Strategy III $(n=105)$ & \\
\hline \multicolumn{5}{|l|}{1 year } \\
\hline Wellbeing score, $\mathrm{mm}$ & $-17(-23$ to -10$)$ & $-21(-28$ to -14$)$ & $-22(-27$ to -16$)$ & \\
\hline Grip strength, $\mathrm{kPa}$ & $+9(+6$ to +12$)$ & $+9(+5$ to +13$)$ & $+14(+10$ to +18$)$ & $\ddagger$ \\
\hline Haemoglobin, mmol/1 & $+0.2(+0.01$ to +0.4$)$ & $+0.3(+0.2$ to +0.5$)$ & $+0.3(+0.2$ to +0.4$)$ & \\
\hline Morning stiffness, min median (10-90 centiles) & $-30(-270$ to +60$)$ & $-45(-178$ to +27$)$ & $-30(-233$ to +23$)$ & \\
\hline $\mathrm{C}$ reactive protein, $\mathrm{mg} / \mathrm{l}$ median $(10-90$ centiles $)$ & $-15(-66$ to +13$)$ & $-9(-94$ to +14$)$ & $-12(-54$ to +5$)$ & \\
\hline Platelet count $\times 10^{9} / 1$ median $(10-90$ centiles $)$ & $-33(-134$ to 29$)$ & $-50(-166$ to +40$)$ & $-45(-177$ to +17$)$ & \\
\hline \multicolumn{5}{|l|}{2 years } \\
\hline Wellbeing score, $\mathrm{mm}$ & $-17(-23$ to -11$)$ & $-24(-30$ to -17$)$ & $-18(-24$ to -12$)$ & \\
\hline Grip strength, $\mathrm{kPa}$ & $+12(+8$ to +15$)$ & $+13(+8$ to +17$)$ & $+15(+11$ to +20$)$ & \\
\hline Haemoglobin, $\mathrm{mmol} / 1$ & $+0.2(+0.04$ to +0.4$)$ & $+0.4(+0.2$ to +0.5$)$ & $+0.4(+0.2$ to +0.5$)$ & \\
\hline Morning stiffness, min median ( $10-90$ centiles $)$ & $-45(-309$ to +36$)$ & $-45(-150$ to +30$)$ & $-30(-216$ to +45$)$ & \\
\hline $\mathrm{C}$ reactive protein, $\mathrm{mg} / \mathrm{l}$ median (10-90 centiles) & $-18(-74$ to +5$)$ & $-11(-95$ to +6$)$ & $-5(-55$ to +5$)$ & \\
\hline Platelet count $\times 10^{9} / 1$ median $(10-90$ centiles $)$ & $-42(-171$ to +29$)$ & $-63(-206$ to +30$)$ & $-50(-173$ to +19$)$ & \\
\hline
\end{tabular}

*Values are the mean change from baseline and $95 \%$ CI for the mean, or the median change and 10-90 centiles, where appropriate.

†Ranges for end points are: wellbeing score 0 to $100 \mathrm{~mm}$; duration of morning stiffness 0 to 720 minutes. Negative values indicate improvement for all end points, except for grip strength and haemoglobin concentration.

‡Differences between strategies were not statistically significant, except for grip strength at one year: difference in change in grip strength between strategies I and III was statistically significant : mean difference is 5 and $95 \%$ CI of the difference is 0.2 to 10.0 , but not between strategies II and III: mean difference is 5 and $95 \%$ CI of the difference is -0.2 to 10.0 


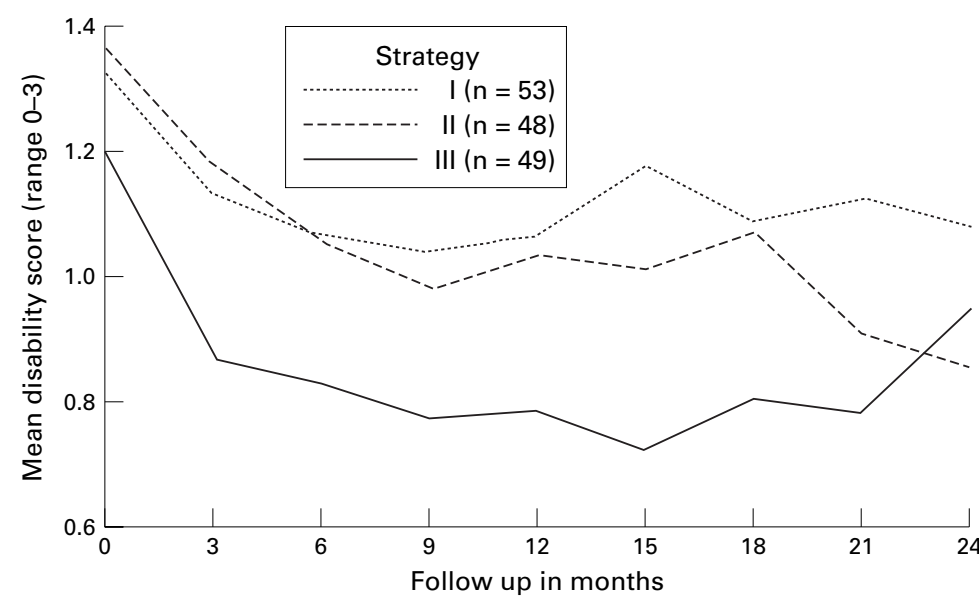

Figure 1 Mean disability score in 150 patients with available data on disability for all nine measurements in each therapeutic strategy. There was a significant difference between strategies I and III ( $p=0.04)$, and a significant decrease in disability over time in each strategy (analysis of variance for repeated measurements).

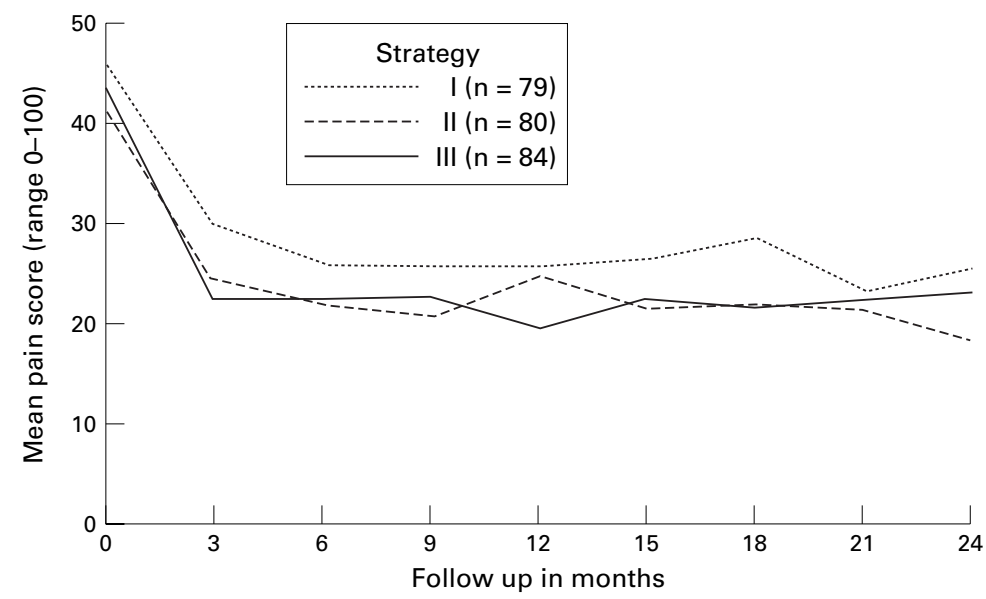

Figure 2 Mean pain score in 243 patients with available data on pain for all nine measurements in each therapeutic strategy. Significant decrease in pain score over time in each strategy, no significant difference between the strategies $(p=0.23)$ (analysis of variance for repeated measurements).

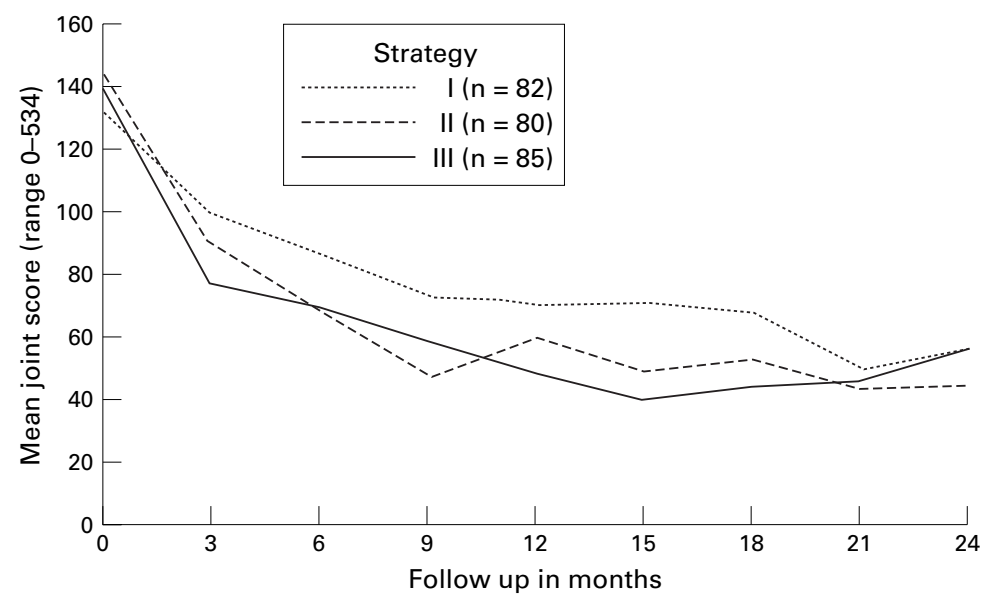

Figure 3 Mean joint score in 247 patients with available data on joint score for all nine measurements in each therapeutic strategy. Significant decrease in joint score over time in each strategy, no significant difference between the strategies $(p=0.30)$ (analysis of variance for repeated measurements).
Thompson joint score was $\leqslant 10$, and the ESR was $\leqslant 30 \mathrm{~mm} / 1 \mathrm{st} \mathrm{h.}{ }^{13}$

PRIMARY END POINTS

Primary end points were pain, functional disability, joint score, ESR, and radiological damage. ${ }^{14}$ Assessments were performed at the start of the trial and repeated every three months, except for radiological damage, which was assessed annually. The same doctor or research nurse assessed clinical variables on each occasion. Functional disability was assessed with a validated Dutch version of the Health Assessment Questionnaire, range 0-3: zero representing the best (no problems) and three the worst score. ${ }^{15} 16$ Pain was measured separately for night and morning on two horizontal visual analogue scales of $100 \mathrm{~mm}$; the mean of the scores was calculated. The joint score according to Thompson assessed the simultaneous presence of joint tenderness and swelling in a selection of joints weighted for joint size; range $0-534 .{ }^{17}{ }^{18}$ Joints that received an injection within two months before an evaluation were not included in the score. ESR in $\mathrm{mm}$ after one hour was measured by the Westergren method. A modified method of Sharp was used to score radiological abnormalities. ${ }^{19} 20$ Erosions and joint space narrowing in hand and foot joints were scored and added to obtain a total score (range 0-448). Two investigators, unaware of the therapeutic strategy, evaluated all radiographs. Investigators evaluated the three consecutive radiographs for each patient in line and were aware of the sequence of radiographs. The scores of the first investigator were used in the analyses; the scores of the second were used to validate the scores of the first. Differences in total scores in individual cases of $25 \%$ or more were discussed until agreement was reached.

\section{SECONDARY END POINTS}

Additional end points were duration of morning stiffness (maximum $720 \mathrm{~min}$ ); general wellbeing (horizontal visual analogue scale of $100 \mathrm{~mm}$ ); grip strength (mean of three measurements of each hand with a Martin vigorimeter in $\mathrm{kPa}$ ); serum concentration of $\mathrm{C}$ reactive protein $(\mathrm{mg} / \mathrm{l})$, haemoglobin concentration $(\mathrm{mmol} / \mathrm{l})$, and platelet count $\left(\times 10^{9} / 1\right)$. Rheumatoid factor status was considered positive if the qualitative Latex fixation test at a dilution of 1:1 was positive or the Rose-Waaler test was positive (that is, titre $\geqslant 40 \mathrm{IU} / \mathrm{ml}$ ), or both. These cut off points result in a positive test in fewer than $5 \%$ of the general population.

\section{STATISTICAL ANALYSIS}

The intention to treat principle was applied; in addition on-protocol or complier analyses were performed including only those patients who continued to be treated according to the randomised strategy. Differences in mean changes from baseline for all end points between the strategies were tested for statistical significance with analysis of variance (ANOVA) or the Kruskal-Wallis test, where appropriate. Radiological damage, morning stiffness, C reactive protein, and platelet count showed a 


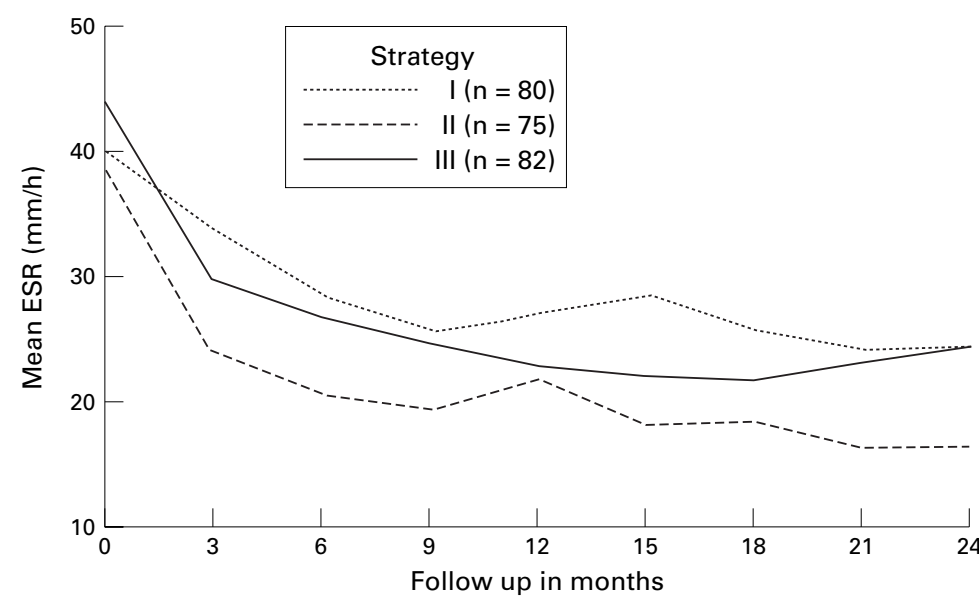

Figure 4 Mean ESR score in 237 patients with available data on ESR for all nine measurements, in each therapeutic strategy. Significant difference between strategies I and II $(p=0.01)$, and significant decrease in ESR over time in each strategy (analysis of variance for repeated measurements).

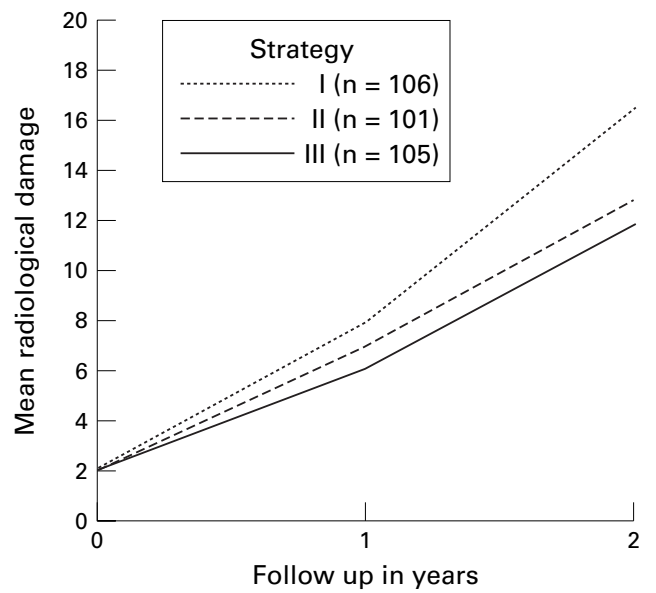

Figure 5 Radiological progression in the three strategies. Significant increase over time in each strategy with significant interaction between overall time-treatment effect and strategy effect, showing a faster increase in strategy $I$ than in strategy II $(p=0.03)$ and strategy III $(p=0.01)$. No significant difference between the three strategies $(p=$ 0.23 ) (analysis of variance for repeated measurements).

skewed distribution. Therefore, median scores were presented for these variables. ANOVA for repeated measurements was used to study differences between the strategies using all the nine three-monthly measurements in analysis. Both the "between-subject" or strategy effects and the "within-subject" or longitudinal time/ overall treatment effects were tested. ANOVA for repeated measurements required variables to show a normal distribution.

Clinically relevant improvement in a single primary end point for individual patients was defined as an improvement of $33 \%$ or more compared with baseline. ${ }^{21}$ Patients were considered to have a clinical response when they improved by $20 \%$ or more compared with baseline on at least three of four primary end points (radiological damage excluded). ${ }^{22}{ }^{23}$ Differences between the strategies were tested for significance with the $\chi^{2}$ test. The definition of remission by Scott et al was used, as mentioned earlier. $^{13}$

No adjustments were made for multiple comparisons. ${ }^{24}$ Power calculations for func- tional disability as one of the primary end points indicated group sizes of 100 to be sufficient for detecting $20 \%$ difference between groups at $\alpha=0.05$ and $1-\beta=0.80$. Statistical analyses were performed with the SPSS for Windows statistical package, version $6.1 .^{25}$

Toxicity was studied in each strategy. As it is notoriously difficult to relate an adverse event to specific drug treatment, all possible adverse events are included in the analysis. ${ }^{26}{ }^{26 a}$ For effectiveness analysis the intention to treat principle was followed. The same applied for toxicity analysis. As a consequence, all adverse events, even if patients discontinued the assigned treatment strategy, were included in this analysis. Most patients $(99 \%)$ also took NSAIDs; therefore, the reported events might also be the result of NSAID use. However, both the rate of events unrelated to antirheumatic drug treatment and NSAID related toxicity are expected to be equally distributed across the three strategies, and consequently not considered to bias the results.

\section{Results}

PATIENT CHARACTERISTICS

In April 1998313 patients had been randomised and had completed at least two years of follow up. Data on 31 randomised patients who were lost to follow up (dropouts) and on 52 patients who did not agree to be randomised were not included in analyses, but baseline characteristics were compared with those of the other groups. Eleven patients $(9 \%)$ in strategy I, $12(11 \%)$ in strategy II, and eight $(7 \%)$ in strategy III were lost to follow up, after a mean period of 7.5 months, which was not significantly different between the strategies. Nine of these 31 dropouts died of causes unrelated to RA or its treatment (cardiac (six patients), respiratory insufficiency (one), malignancy (one), sepsis (one)); four patients were excluded because of other serious disease processes (coronary heart disease, malignancy, lung disease, immobility due to car accident); in three cases the diagnosis of RA turned out to be incorrect (systemic lupus erythematosus (two), no chronic rheumatic disease (one)); one patient moved out of the study region; 14 patients refused to be treated following the protocol despite initial consent (two from strategy I, six from II, and six from III).

Table 1 shows baseline characteristics of all the patients. The male/female ratio is typical for an RA population. Mean age was rather high for patients with recent onset RA, but in line with recent epidemiological data in the Netherlands. ${ }^{27}$ Disease duration of all patients was less than one year. Baseline disease status for the randomised groups was comparable and indicated a relatively active disease. Baseline characteristics of the 31 patients lost to follow up were in general comparable with those of the therapeutic groups, except that these patients were older. Death was one of the main reasons for dropout, which might explain the higher age. The 52 patients who did not agree to be randomised had slightly better baseline values (table 1 ). 


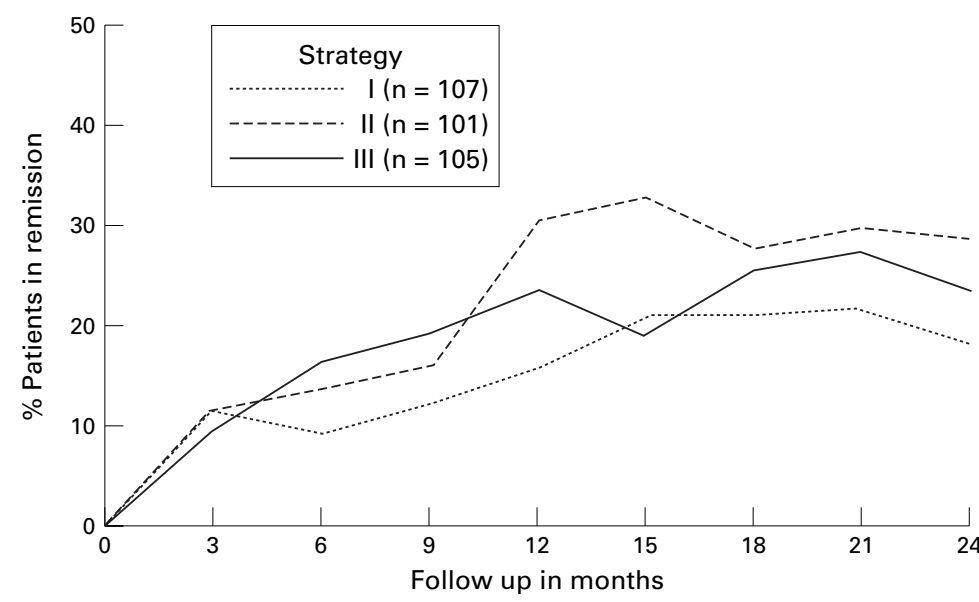

Figure 6 Percentage of patients in remission at each measurement in time. Remission is defined as morning stiffness $\leq 15 \mathrm{~min}$, pain score $\leq 10 \mathrm{~mm}$, joint score $\leq 10$, and ESR $\leq 30$ $\mathrm{mm} / 1 \mathrm{st} \mathrm{h}$.

Table 5 Patients with clinically relevant improvement ${ }^{\star}$, clinical responset, and remission $\neq$ after one and two years

\begin{tabular}{|c|c|c|c|c|}
\hline & \multicolumn{3}{|c|}{ No (\%) patients } & \multirow{2}{*}{$\begin{array}{l}\text { Difference between strategies } \\
p \text { value } \chi^{2} \text { test }\end{array}$} \\
\hline & Strategy I & Strategy II & Strategy III & \\
\hline \multicolumn{5}{|l|}{1 year $\$$} \\
\hline Disability & 39 (39) & $46(52)$ & $51(53)$ & NS \\
\hline Pain score & $70(67)$ & $63(64)$ & $75(72)$ & NS \\
\hline Joint score & $71(66)$ & $80(79)$ & $86(82)$ & I $v$ II: $\mathrm{p}=0.04 ; \mathrm{I} v$ III: $\mathrm{p}=0.01$ \\
\hline ESR & $60(56)$ & $64(63)$ & $71(68)$ & NS \\
\hline Clinical response & $58(56)$ & $61(64)$ & $72(71)$ & NS \\
\hline Remission & $17(16)$ & $31(31)$ & $25(24)$ & I $v$ II: $\mathrm{p}=0.01 ; \mathrm{III} v \mathrm{I} / \mathrm{II}: \mathrm{NS}$ \\
\hline \multicolumn{5}{|l|}{2 years $\$$} \\
\hline Disability & $40(41)$ & $39(47)$ & $45(47)$ & NS \\
\hline Pain score & $67(64)$ & $71(73)$ & $65(63)$ & NS \\
\hline Joint score & $80(75)$ & $78(78)$ & $80(76)$ & NS \\
\hline ESR & $68(64)$ & $67(67)$ & $69(66)$ & NS \\
\hline Clinical response & $63(61)$ & $68(71)$ & $64(63)$ & NS \\
\hline Remission & $20(19)$ & $29(29)$ & $25(24)$ & NS \\
\hline
\end{tabular}

${ }^{\star}$ Clinically relevant improvement is $\geqslant 33 \%$ improvement after one and two years respectively from baseline.

†Clinical response is $\geqslant 20 \%$ improvement on three or four end points.

$\ddagger$ Remission: morning stiffness $\leq 15$ minutes, pain score $\leq 10 \mathrm{~mm}$, joint score $\leq 1$, and ESR $\leq 30$ $\mathrm{mm} / 1 \mathrm{st} h$ at respectively one or two years.

\At year 1 data were missing for improvement on disability (27 patients), pain (7), ESR (1), clinical response (11); at year 2 data were missing for improvement on disability (37), pain (8), joint score (1), ESR (1), clinical response (13), and remission (2).

NS $=$ not significantly different. the dose was increased to $17.5-25 \mathrm{mg}$. Folic acid $(0.5 \mathrm{mg}$ six days a week; not on the day of methotrexate intake) was used by $33 \%$ of patients. Folic acid was used more in patients receiving higher doses of methotrexate: $45 \%$ of patients using $10 \mathrm{mg} /$ week methotrexate, or higher doses, compared with $21 \%$ of patients receiving methotrexate $7.5 \mathrm{mg} /$ weekly.

\section{CORTICOSTEROIDS}

Restricted use of oral corticosteroids as adjuvant treatment appeared to be unavoidable in comparable percentages of patients in each of the three strategies: $8 \%$ during the first year and $12 \%$ during both years. Intra-articular injections were given at least once to $28 \%$ of the patients during the first year and to $44 \%$ during both years. No significant difference in this respect between the three strategies was found.

\section{EFFECTIVENESS}

\section{Changes from baseline}

Changes from baseline were significant for all primary end points in each strategy, indicated by the $95 \%$ confidence intervals of the mean changes (table 3). Improvement seemed slightly less in strategy I than in the other strategies. However, no significant differences in change scores were observed between the three strategies, except for radiological damage. Although radiological progression was rather small, median scores after one and two years were significantly worse for strategy I than for strategies II or III. Complier analyses also showed no significant differences between the three strategies, except for radiological damage at one year, which was again high in strategy I (data not shown). All secondary end points also improved significantly from baseline in each strategy. Differences between the strategies were small and statistically not significant, except for improvement in grip strength after the first year which was significantly less in strategy I than in III (table 4).

\section{Longitudinal trends}

Figures 1 to 5 show longitudinal trends in the primary end points. Analysis for repeated measurements included only those subjects with complete data at all measurements during the two years: disability (150 patients), pain score (243), joint score (247), ESR (237), and radiological damage (312). Disability over time was favourable in strategy III compared with I (fig $1, p=0.04$ ). There was no significant difference between the three strategies for pain (fig 2) and joint scores (fig 3). The ESR over time was significantly higher in strategy I than in II (fig 4, p = 0.01). Results showed significant decreases in disability, pain, joint score, and ESR over time in all three strategies. Figure 5 shows the radiological progression. Owing to the skewed distribution of radiological damage, median scores are presented instead of means. Square root transformed data, which showed a normal distribution, were used in repeated measurement analysis. A significant increase in the radiological damage score over time was seen in each strategy with maximum weekly dose of methotrexate was 7.5 $\mathrm{mg}$ in $51 \%$ of the patients, $10-15 \mathrm{mg}$ in $43 \%$, and in $6 \%$ the study protocol was violated and 
Table 6 Clinical symptoms and laboratory abnormalities in each treatment strategy

\begin{tabular}{|c|c|c|c|}
\hline & Strategy $I$ & Strategy II & Strategy III \\
\hline \multicolumn{4}{|l|}{ Gastrointestinal (subjective) } \\
\hline Nausea, vomiting, dyspepsia, epigastric pain, indigestion & 35 & 21 & 39 \\
\hline Diarrhoea & 17 & 7 & 5 \\
\hline Dysgeusia & - & 4 & 1 \\
\hline \multicolumn{4}{|l|}{ Gastrointestinal (objective) } \\
\hline Gastric ulcer & 1 & 1 & 1 \\
\hline Gastritis & - & - & 2 \\
\hline Gastrointestinal bleeding & - & - & 1 \\
\hline Colitis & 1 & - & 1 \\
\hline Colorectal surgery & 1 & - & - \\
\hline \multicolumn{4}{|l|}{ Mucocutaneous } \\
\hline Rash & 17 & 47 & 10 \\
\hline Stomatitis, mouth ulcers & 2 & 12 & 4 \\
\hline Alopecia & 1 & 3 & 7 \\
\hline Photosensitivity & 1 & - & - \\
\hline \multicolumn{4}{|l|}{ Central nervous system } \\
\hline Headache, dizziness, tinnitus, mood alterations & 9 & 7 & 9 \\
\hline Concentration disturbances & 5 & - & 1 \\
\hline \multicolumn{4}{|l|}{ Renal } \\
\hline Proteinuria $(>0.1 \mathrm{~g} / 1$ in $24 \mathrm{~h})$ & 2 & 11 & 2 \\
\hline Raised serum creatinine $(>120 \mu \mathrm{mol} / \mathrm{l})$ & 7 & 8 & 9 \\
\hline Oedema (pretibial) & 2 & 3 & 3 \\
\hline Haematuria (macroscopic observation) & - & 1 & 2 \\
\hline Foul odour urine & - & 1 & 1 \\
\hline \multicolumn{4}{|l|}{ Hepatotoxicity } \\
\hline Raised transaminases or $\gamma \mathrm{GT}^{\star}\left(\mathrm{ALAT}^{\star}>90 \mathrm{U} / 1, \gamma \mathrm{GT}>100 \mathrm{U} / \mathrm{l}\right)$ & 7 & 9 & 23 \\
\hline \multicolumn{4}{|l|}{ Haematological } \\
\hline Anaemia $(\mathrm{Hb}<6.5 \mathrm{mmol} / \mathrm{l})$ & 21 & 12 & 9 \\
\hline Leucopenia $\left(<3.5 \times 10^{9} / 1\right)$ & - & 9 & 3 \\
\hline Thrombocytopenia $\left(<150 \times 10^{9} / 1\right)$ & 3 & 10 & 6 \\
\hline Eosinophilia $\left(>0.5 \times 10^{9} / 1\right)$ & - & 2 & - \\
\hline Pancytopenia & - & 1 & - \\
\hline Leucopenia and thrombocytopenia & - & 2 & - \\
\hline \multicolumn{4}{|l|}{ Respiratory system } \\
\hline Persistent cough & 1 & 3 & 3 \\
\hline Dyspnoea & 1 & 2 & 1 \\
\hline Pneumonitis & - & 1 & 1 \\
\hline Pulmonary disorder (other than pneumonitis) & 2 & 1 & 1 \\
\hline \multicolumn{4}{|l|}{ Disorders of eye or ear } \\
\hline Disturbed vision (unspecified) & 4 & 2 & 5 \\
\hline Cataract & - & 1 & 3 \\
\hline Blepharitis & 2 & 1 & - \\
\hline Conjunctivitis & 1 & - & - \\
\hline Scleritis & - & 1 & - \\
\hline Toxic keratitis & - & - & 1 \\
\hline Ocular sarcoidosis & 1 & - & - \\
\hline Glaucoma & - & 1 & - \\
\hline Dry eyes/dry mouth & - & 1 & - \\
\hline Impaired hearing & - & 1 & - \\
\hline \multicolumn{4}{|l|}{ Other } \\
\hline Fever, infections & 12 & 12 & 18 \\
\hline Rheumatoid nodulosis & 4 & 3 & 2 \\
\hline Weight loss & 4 & 3 & - \\
\hline Fatigue & 3 & - & 2 \\
\hline Neuropathy & 1 & 2 & 1 \\
\hline Vertebral fracture, osteoporosis & 1 & 1 & 2 \\
\hline Malignancy & - & 2 & 2 \\
\hline Heart failure & - & 2 & - \\
\hline Sexual impotence & - & 1 & - \\
\hline Restless legs & 1 & - & - \\
\hline Total & 170 & 212 & 181 \\
\hline
\end{tabular}

${ }^{\star} \gamma \mathrm{GT}=\gamma$-glutamyl transferase; ALAT $=$ alanine aminotransferase.

significant interaction between longitudinal treatment effect and strategy effect, showing a faster increase in strategy I than in strategies II $(\mathrm{p}=0.03)$ or III $(\mathrm{p}=0.01)$. Progression in strategies II and III was comparable $(p=0.67)$.

Lag time until treatment effect

The lag time until treatment effect was deduced from the slopes of the lines during the first months. Figures 1, 2, and 3 show no clear differences in lag time between the three strategies, whereas the change in ESR occurred faster in strategies II and III than in I (fig 4). During the first months the slope was steeper in strategies II and III, and levelled off after about three months, whereas the slope in strategy I was less steep and levelled off after about nine months. These numerical differences did not reach statistical significance.
Clinical improvement

Table 5 shows the percentage of patients exhibiting clinical improvement. At one year the percentage of patients whose joint score had improved was 79 in strategy II and 82 in III, which is better than in strategy I $(66 \%)(\mathrm{p}$ $=0.02)$. Remission rates at one year were also higher in strategies II $(31 \%)$ and III $(24 \%)$ than in strategy I $(16 \%, \mathrm{p}=0.04)$, but no obvious differences were seen at two years. Complier analysis showed higher clinical improvement and remission rates in strategy III at one year compared with strategies I or II (not statistically significant). At year two, clinical response rate was high in strategy II $(80 \%)$ compared with strategies I $(61 \%)$ or III $(63 \%)$ $(p=0.03)$ (data not shown). Figure 6 shows the percentage of patients fulfilling remission criteria at a single measurement (intention to treat 
analysis). Remission rates were slightly higher in the complier analysis $(27 \%)$ at two years than in the intention to treat analysis $(24 \%)$.

\section{TOXICITY}

Investigation of toxicity included threemonthly clinical reports and laboratory abnormalities. All reported or observed symptoms were included (table 6). Most patients (99\%) also took NSAIDs. Therefore, the reported events might also have been the result of NSAID use. In strategy I most events were subjective gastrointestinal complaints (52), followed by anaemia (21), and rash (17). Mucocutaneous reactions occurred most commonly in strategy II (62); subjective gastrointestinal complaints and hepatotoxicity were most commonly seen in strategy III, and renal toxicity was more commonly seen in strategies II (24) and III (17) than in strategy I (11). These observations are in line with other published reports. ${ }^{28}$

Most patients reported toxicity (240, 77\%): at least one "adverse" event was reported by 76 patients $(71 \%)$ in strategy I, $81(77 \%)$ in strategy III, and in $83(82 \%)$ in strategy II. The mean number of events for each patient was high in strategy II: 2.1 , compared with 1.6 in strategy I and 1.7 in strategy III. Most events were mild, not leading to any change in dose or type of SAARD (432 of 563 events, $77 \%$ ). Fifty two events led to dose adjustments of SAARD (18 in strategy I, 17 in II, and 17 in III). A total of 79 events led to permanent discontinuation of an SAARD, which occurred more often in strategy II (46 events) than in strategies I (17) or III (16). In strategy II (46 events) the drugs discontinued were IM gold in 30 cases, D-penicillamine in 11 cases, and other SAARDs in five. The drugs discontinued permanently owing to toxicity in strategy I were hydroxychloroquine in 10 cases and auranofin in five cases and in strategy III were methotrexate in 11 and sulfasalazine in four cases, and other SAARDs for the remaining cases.

All events were reversible, apart from four reported malignancies (breast, skin, nasopharyngeal, and oesophagus carcinoma) and one pulmonary disorder (other than pneumonitis). The malignancies were probably unrelated to treatment. One case of pneumonitis occurred in strategy II during IM gold treatment and one in strategy III during methotrexate treatment. A more detailed description of toxicity related to the initial randomised drugs has been performed. ${ }^{26 a}$

\section{Discussion}

In this randomised study a comparison of three therapeutic strategies was made for patients with recently diagnosed RA. This study is considered representative for patients with RA referred to hospital, as all patients with recent onset RA attending six rheumatological centres, who fulfilled the inclusion criteria, were asked to participate. The study is not community based as the population base referred to patients with RA attending a rheumatological centre (specialised setting). The results are applicable to patients with early RA presenting to a rheumatologist (that is, hospital based). To enrol the majority of the patients and obtain an unselected sample of patients, from whom results are applicable to clinical practice, only a small number of exclusion criteria were used. Although the open label design applied in this study might enhance bias in effectiveness and toxicity assessments, its protocol is closely connected to clinical practice. Consequently, the effectiveness (effects under ordinary circumstances - that is, the pragmatic approach) rather than efficacy (effects under ideal conditions) of treatment was studied. ${ }^{29} 30$

This study showed significant improvements on all primary and secondary end points (except for radiological damage) for all three strategies. The differences between the strategies favoured strategies II and III rather than strategy I; however, this was only statistically significant for improvement in joint score and remission at one year. Longitudinal analysis showed less functional disability in strategy III, and lower ESR in strategy II than in strategy I. In addition, radiological damage after one and two years was significantly lower in strategies II and III than in strategy I. Radiological progression during the first two years of disease was small in all strategies, which might be the result of the early introduction of SAARD treatment. Consequently, the differences found at two years are not of major clinical importance. However, if linear progression proceeds at the same rate in subsequent years, differences between the strategies may become clinically significant.

The two-year analyses showed few statistically significant differences between the strategies apart from the significantly greater radiological progression in strategy I. However, trends in the other primary end points all favour strategies II or III. Therefore, we conclude that effectiveness in strategies II and III was superior to that of strategy I. No significant differences were observed between strategies II and III, though this study is too small to dissociate clearly between these strategies. Strategy II has minor disadvantages-namely, slightly more radiological progression and toxicity. Strategy III comprised methotrexate with a maximum dose of $15 \mathrm{mg}$ weekly; $43 \%$ of patients treated with methotrexate exceeded a weekly dose of $7.5 \mathrm{mg}$ and another $6 \%$ exceeded $15 \mathrm{mg}$. Recently, higher doses are being used, even in early RA. The effectiveness and toxicity of higher doses are to be evaluated.

After two years, $80 \%$ of the patients in strategy III were still treated according to the randomised strategy, which was slightly higher than the $73 \%$ in strategy I and $70 \%$ in II. Complier analysis showed similar results to those of the intention to treat analysis, with slightly better effectiveness for strategy II, suggesting that if IM gold (followed by D-penicillamine) had not been discontinued owing to side effects, strategy II would have been as effective as strategy III or even a little better. The higher rate of toxicity in strategy II is an obvious disadvantage.

This study focuses on treatment strategies rather than on specific drugs, which increases 
the number of patients continuing treatment. The characterisation of strategy I as being mild seems justified. Effectiveness was less than for the other strategies and toxicity was less than in strategy II. The characterisation of strategy II and III as including more potent SAARDs also seems correct in terms of effectiveness, which was better than that of strategy I. The toxicity rate in strategy II was high compared with strategy III, indicating that SAARDs used in strategy II are more toxic than the SAARDs in strategy III, in the prescribed dosages. As for the characterisation of the strategies according to the length of the lag time until treatment effect, it is concluded that strategy $I$ is associated with a long lag time and III with a relatively short lag time. The assumption that strategy II was also associated with a long lag time was shown to be incorrect; similar slopes were seen for strategies II and III. Since our first measurement was after three months, no conclusions can be drawn for the preceding months.

Although we did not compare single drugs, we believe that the effectiveness measured after one year is mainly the effect of the initial randomised drug. This is less true at two years, since the initial randomised SAARD was still used by $86 \%$ after one year but by only $47 \%$ after two years of follow up. Other studies on the effectiveness of SAARDs were often of shorter duration, or included fewer patients. Summarising these studies, moderate effectiveness of hydroxychloroquine and auranofin has been reported, ${ }^{5}{ }^{31}$ while better effectiveness for other SAARDs has been found, without clear differences between these SAARDs. ${ }^{11}{ }^{32-34}$ As for radiological damage, patients treated with IM gold, methotrexate, or sulfasalazine had a slower progression than those treated with hydroxychloroquine, auranofin, or azathioprine when three different trials were compared..$^{20}{ }^{35-37}$ At five years, greater progression was found for D-penicillamine than for methotrexate. ${ }^{38}$

SAARDs have been shown to reduce disease activity, but remission occurs in a minority of patients. Although the definitions of remission differ between studies, the reported remission rates are concordant, and never exceed $25 \%$. $^{783940}$ Remission rates of $24 \%$ after two years for patients treated with IM gold and $12 \%$ in patients treated with methotrexate have been reported. ${ }^{81}$ In 257 patients with early RA, followed up for four years only $15 \%$ fulfilled remission criteria for at least two consecutive visits. ${ }^{42}$ In our study remission rates at one year varied from 16 to $31 \%$ and at two years from 19 to $29 \%$. Although these rates are in concordance with earlier studies, we believe that the ultimate goal in treating RA-that is, a lasting clinical remission, is achieved in too few cases. Other treatment options are to be searched for to increase remission rates. Combination treatment, including more than one SAARD at the same time or new biological agents, has not been shown to be clearly superior, but may be of interest and needs further evaluation. ${ }^{43}$ As this and our previous study show, the early start of an SAARD is probably more important than the choice of the SAARD. ${ }^{3}$ In addition intensive, individualised treatment might increase treatment effectiveness, which might need a paradigm shift from aiming for improvement to aiming for remission.

The authors wish to acknowledge C Cornelis, R Huisman, A Jacobs-van Bree, van Mourik, and S van Wijk for the collection of data and their contributions to the Utrecht Rheumatoid Arthritis Cohort. Grant support: The Dutch League against Rheumatism (Het Nationaal Reumafonds).

1 Roth SH. Rethinking rheumatic disease therapy. J Rheumatol 1989;16:1408-9.

2 Wilske KR, Healey LA. Challenging the therapeutic pyramid: a new look at treatment strategies for rheumatoid arthritis. J Rheumatol 1990;17:4-7.

3 van der Heide A, Jacobs JWG, Biilsma JWJ, Heurkens $\mathrm{AHM}$, van Booma-Frankfort C, van der Veen MJ, et al. The effectiveness of early treatment with "second-line" antirheumatic drugs: a randomized, controlled trial. Ann antirheumatic drugs: a randon.

4 Intern Med 1996;124:699-707. Nuver-Zwart IH, van Riel PLCM, van de Putte LBA, Grib-
nau FWJ. A double blind comparative study of sulphasalanau FWJ. A double blind comparative study of sulphasala-
zine and hydroxychloroquine in rheumatoid arthritis: zine and hydroxychloroquine in rheumatoid arthritis: evidence of an earlier
Dis 1989;48:389-95.

5 Gis 1989;48:389-95. Karstensen B, Brodin U. Auranofin is safe and superior to placebo in elderly-onset rheumatoid arthritis. Br J Rheumatol 1997;36:870-7.

6 Felson DT, Anderson JJ, Meenan RF. The comparative efficacy and toxicity of second-line drugs in rheumatoid arthritis - results of two meta-analyses. Arthritis Rheum 1990;33:1449-61.

7 Jones G, Brooks PM. Injectable gold compounds: an overview. Br J Rheumatol 1996;35:1154-8.

8 Rau R, Herborn G, Menninger H, Blechschmidt J. Comparison of intramuscular methotrexate and gold sodium thiomalate in the treatment of early erosive rheumatoid arthritis: 12 month data of a double-blind parrheumatoid arthritis: 12 month data of a double-blind par-
allel study of 174 patients. Br J Rheumatol 1997;36:34552 .

9 Situnayake $\mathrm{RD}$, Grindulis KA, McConkey B. Long term treatment of rheumatoid arthritis with sulphasalazine, gold, or penicillamine: a comparison using life-table methods. Ann Rheum Dis 1987;46:177-83.

10 Segal R, Caspi D, Tishler M, Wigler I, Yaron M. Short term effects of low dose methotrexate on the acute phase reaction in patients with rheumatoid arthritis. J Rheumatol 1989;16:914-17.

11 Farr M, Bacon PA, Coppock J, Scott DL. Long term experience of salazopyrin EN in rheumatoid arthritis (RA). Scand J Rheumatol 1987;64:37-47.

12 Arnett FC, Edworthy SM, Bloch DA, McShane DJ, Fries JF, Cooper NS, et al. The American Rheumatism Association 1987 revised criteria for the classification of rheumatoid arthritis. Arthritis Rheum 1988;31: $315-24$.

13 Scott DL, Spector TD, Pullar T, McConkey B. What should we achieve when treating rheumatoid arthritis? Ann Rheum Dis 1989;48:256-61

14 van der Heide A, Jacobs JWG, Dinant HJ, Bijlsma JWJ. The impact of endpoint measures in rheumatoid arthritis clinical trials. Semin Arthritis Rheum 1992;21: $287-94$

15 Bijlsma JWJ, Oude Heuvel CHB, Zaalberg A. Development and validation of the Dutch questionnaire capacities of daily life (VDF) for patients with rheumatoid arthritis. Journal of Rehabilitation Sciences 1990;3:71-4.

16 van der Heide A, Jacobs JWG, van Albada-Kuipers GA, Kraaimaat FW, Geenen R, Bijlsma JWJ. Self report functional disability scores and the use of devices: two distinct aspects of physical function in rheumatoid arthritis. Ann Rheum Dis 1993;52:497-502.

17 Thompson PW, Silman AJ, Kirwan JR, Currey HLF. Articular indices for joint inflammation with rheumatoid arthritis. Correlation with the acute-phase response. arthritis. Correlation with the

18 van den Brink HR, van der Heide A, Jacobs JWG, van der Veen MJ, Bijlsma JWJ. Evaluation of the Thompson articular index. J Rheumatol 1993;20:28-32.

19 Sharp JT, Young JT, Bluhm GB, Brook A, Brower AC, Corbett $M$, et al. How many hands and wrists should be included in a score of radiologic abnormalities used to assess rheumatoid arthritis? Arthritis Rheum 1985;28: $1326-35$.

20 van der Heijde DMFM, van Riel PLCM, Nuver-Zwart IH, Gribnau FW, van de Putte LBA. Effects of hydroxychloroquine and sulphasalazine on progression of joint damage in rheumatoid arthritis. Lancet 1989;i:1036-8.

21 Goldsmith CH, Boers M, Bombardier C, Tugwell P. Criteria for clinically important changes in outcomes: development, scoring and evaluation of rheumatoid arthritis patient and trial profiles. J Rheumatol 1993;20:

2 Felson DT, Anderson JJ, Boers M, Bombardier C, Furst D, Goldsmith C, et al. American College of Rheumatology preliminary definition of improvement in rheumatoid arthritis. Arthritis Rheum 1995;38:727-35. 
23 Paulus H, Egger MJ, Ward JR, Williams HJ, and the Cooperative Systematic Studies of Rheumatic Diseases Group. Analysis of improvement in individual rheumatoid arthritis patients treated with disease-modifying anti-rheumatic drugs, based on the findings in patient
placebo. Arthritis Rheum 1990;33:477-84.

24 Rothman KJ. No adjustments are needed for multiple comparisons. Epidemiology 1990;1:43-6.

25 Norusis MJ. SPSS 6.1 advantaged statistics user's guide. Chigaco: SPSS Inc, 1990

26 Naranjo CA, Busto U, Sellers EM, Sandor P, Ruiz I, Roberts EA, et al. A method for estimating the probability of adverse drug reactions. Clin Pharmacol Ther 1981;30: 239-45.

26a van Jaarsveld CHM, Jahangier ZN, Jacobs JWG, Blaauw AAM, Brus HLM, van Albada-Kuipers GA, et al. Toxicity of anti-rheumatic drugs in a randomized clinical trial of early rheumatoid arthritis [abstract]. Arthritis Rheum 1998;41(suppl):S271.

27 Miedema HS, Linden van de SM, Rasker JJ, Valkenburg HA. National database of patients visiting rheumatologists in the Netherlands: the standard diagnosis register of rheuin the Netherlands: the standard diagnosis register of rheu-
matic diseases. A report and preliminary analysis. $\mathrm{Br} \mathrm{J}$ matic diseases. A report an

28 American College of Rheumatology. Guidelines for monitoring drug therapy in rheumatoid arthritis. Arthritis Rheum 1996;39:723-31.

29 Fletcher RH, Fletcher SW, Wagner EH. Clinical epidemiology - the essentials. Baltimore: Williams and Wilkins, 1988.

30 Schwartz D, Lellouch J. Explanatory and pragmatic attitudes in therapeutical trials. J Chron Dis 1967;20:63748.

31 Clark P, Casas E, Tugwell P, Medina C, Gheno C, Tenorio $\mathrm{G}$, et al. Hydroxychloroquine compared with placebo in rheumatoid arthritis. A randomized controlled trial. Intern Med 1993;119:1067-71.

32 Suarez-Almazor ME, Russell AS. Parenteral methotrexate or gold for rheumatoid arthritis: a follow up. Clin Exp or gold for rheumatoid arth

33 Situnayake RD, McConkey B. Clinical and laboratory effects of prolonged therapy with sulfasalazine, gold or effects of prolonged therapy with sulfasalazine, gold or penicillamine: the effects of disease duration
response. J Rheumatol 1990;17:1268-73.

34 Haagsma CJ, Russel FG, Vree TB, van Riel PL, van de Putte LB. Combination of methotrexate and sulphasalazine in patients with rheumatoid arthritis: pharmacokinetic analysis and relationship to clinical response. Br J Clin Pharmacol 1996;42:195-200.
35 van Riel PL, van der Heijde DM, Nuver Zwart IH, van de Putte LB. Radiographic progression in rheumatoid arthritis: results of 3 comparative trials. J Rheumatol 1995; 22:1797-9.

36 Lopez Mendez A, Daniel WW, Reading JC, Ward JR, Alarcon GS. Radiographic assessment of disease progression in rheumatoid arthritis patients enrolled in the cooperative systematic studies of the rheumatic diseases program randomized clinical trial of methotrexate, auranofin, or a combination of the two. Arthritis Rheum 1993;36:1364-9.

37 Weinblatt ME, Polisson R, Blotner SD, Sosman JL, Aliabadi $\mathrm{P}$, Baker $\mathrm{N}$, et al. The effects of drug therapy on radiographic progression of rheumatoid arthritis. Results of a 36-week randomized trial comparing methotrexate and auranofin. Arthritis Rheum 1993;36:613-19.

38 Drosos AA, Tsifetaki N, Tsiakou EK, Timpanidou M, Tsampoulas C, Tatsis CK, et al. Influence of methotrexate on radiographic progression in rheumatoid arthritis: a sixty-month prospective study. Clin Exp Rheumatol 1997; 15:263-7.

39 Harrison BJ, Symmons DP, Brennan P, Barrett EM, Silman AJ. Natural remission in inflammatory polyarthritis: issues of definition and prediction. $\mathrm{Br}$ J Rheumatol 1996;35: 1096-100.

40 Eberhardt K, Rydgren L, Fex E, Svensson B, Wollheim FA. D-penicillamine in early rheumatoid arthritis: experience from a 2-year double blind placebo controlled study. Clin Exp Rheumatol 1996;14:625-31.

41 Rau R, Herborn G, Karger T, Menninger H, Elhardt D, Schmitt J. A double blind randomized parallel trial of intramuscular methotrexate and gold sodium thiomalate in early erosive rheumatoid arthritis. J Rheumatol 1991;18: early erosiv $328-33$.

42 Prevoo MLL, van Gestel AM, van't Hof MA, van Rijswijk MH, van de Putte LBA, van Riel PLCM. Remission in a prospective study of patients with rheumatoid arthritis. American Rheumatism Association preliminary remission criteria in relation to the disease activity score. Br J Rheumatol 1996;35:1101-5.

43 Boers M, Verhoeven AC, Markusse HM, van de Laar MA, Westhovens R, van Denderen JC, et al. Randomised comparison of combined step-down prednisolone, methotrexate and sulphasalazine with sulphasalazine alone in early rheumatoid arthritis. Lancet 1997;350:309-18. 